\title{
Improvement of Severe Gummy Smile by Botulinum Toxin Application and Gingivoplasty
}

\author{
Dr. Irineu Gregnanin Pedron ${ }^{1}$
}

${ }^{1}$ Bottoxindent Institute, São Paulo, Brazil.

\begin{abstract}
Currently, the search for aesthetic excellence has become the main objective in the dental treatment. The gummy smile is one of the complaints from the patients, since this situation may influence their self-esteem and social relationship. The development of new techniques, such as the application of botulinum toxin, may be a therapeutic option more conservative, in the treatment of gummy smile. The purpose of this article is to present a case of a patient with dentogingival discrepancy and severe gummy smile, who was treated with gingivoplasty and application of botulinum toxin in order to optimise the harmony of the smile.

Keywords: Botulinum toxins type A; gingival overgrowth; gingivectomy; gingivoplasty; gummy smile; surgical crown lengthening.
\end{abstract}

\section{INTRODUCTION}

Currently, the search for aesthetic procedures has grown exponentially. Dental procedures, as well as medical, besides craving the principle of promoting health, look for smile aesthetics..$^{1-3}$

The facial aesthetic harmony is formed by the union of three components: teeth, gingiva and lips. ${ }^{1-4}$ The smile becomes aesthetically pleasing when these elements are arranged in suitable proportion, and gingival exposure is limited to $3 \mathrm{~mm}$. When gingival exposure is larger than $3 \mathrm{~mm}$, it characterises a non-aesthetic condition called gummy smile, which affects some patients psychologically. . $^{1,5-7}$

Several therapeutic modalities were proposed for the correction of gummy smile, among them are gingivoplasty, ${ }^{1-7}$ myectomy, ${ }^{6}$ and orthognathic surgery. ${ }^{6-8}$ The last two procedures are more invasive and present high morbidity. ${ }^{1}$ On the other hand, the use of botulinum toxin can be considered as a therapeutic option to the surgical procedure, as it is a method more conservative, effective, faster and safer, when compared to surgical procedures. ${ }^{1,5,9}$

Botulinum toxin is synthesised by the anaerobic Grampositive Clostridium botulinum bacterium, and inhibits the release of acetylcholine at the neuromuscular junction, impeding the muscle contraction. ${ }^{1,6-8}$ There are seven distinct

\footnotetext{
Correspondence:

Dr. Irineu Gregnanin Pedron

Rua Flores do Piauí, 508 - São Paulo,

Brazil - Zip Code: 08210-200..

email: igpedron@alumni.usp.br

Citation

Pedron IG. Improvement of Severe Gummy Smile by Botulinum Toxin Application and Gingivoplasty. J Nepal Soc Perio Oral Implantol. 2018;2(2):67-9.
}

serotypes of the toxin and the type A is the most frequently used clinically and it is a stronger subtype..$^{1,6}$

The botulinum toxin has shown efficiency in the treatment of gummy smile, as well as other disorders such as temporomandibular dysfunction (bruxism, clenching and masseteric hypertrophy) and orofacial pains. ${ }^{1,4-10}$ The purpose of this article was to report a case of a patient who presented severe gummy smile and was treated by associating gingivoplasty and botulinum toxin.

\section{CASE REPORT}

A female patient, 34-year-old, attended the particular clinic complaining of gummy smile (Figure 1). Clinically, the patient presented anatomic discrepancy between the length of the maxillary teeth, and severe gummy smile, with more than $4 \mathrm{~mm}$ (Figure 2). Systemic alterations were not reported. Gingivoplasty was suggested. However, the application of botulinum toxin was proposed to complement the result of gingivoplasty. Additionally, the patient was counseled about the recurrence of the gummy smile after six months of the application. The patient agreed with the proposed treatment and signed the term of consent for the application of botulinum toxin.

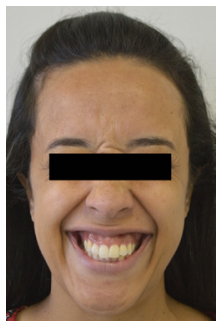

Figure 1: Severe gingival exposure, characterising gummy smile.

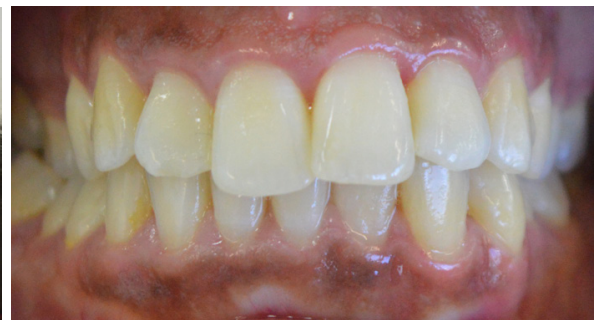

Figure 2: Intraoral clinical aspect presenting anatomic discrepancy between the maxillary teeth. 


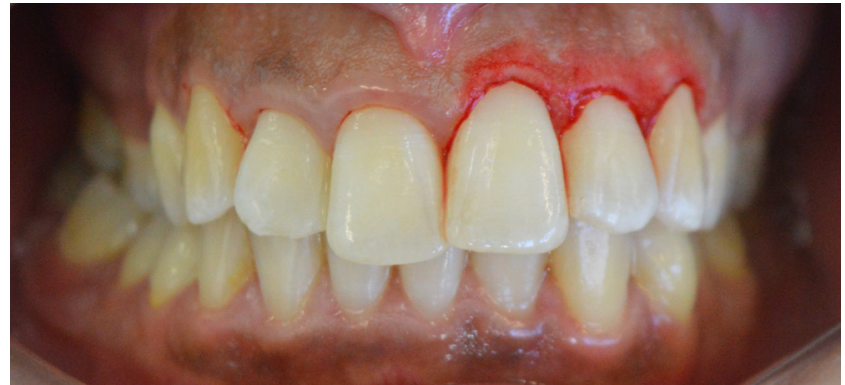

Figure 3: Immediate post-operative view of the teeth 21, 22 and 23.

Under local infiltrative anaesthesia, gingivoplasty was performed, by the determination of the bleeding points with the aid of a millimeter probe and the union of these points was made with the electric scalpel. ${ }^{2}$ The length of the teeth was increased, characterising the dental zenith. Posteriorly, the scraping was performed, resembling the technique of external bevel, with the purpose of increasing the tissue reparation (Figure 3,4). There was no need for the surgical cement, given that the wound repair process occurs by second intention. The patient was oriented and analgesics were administered postoperatively.

After 30 days, satisfactory tissue reparation was observed (Figure 5) and the patient reported no changes or complaints. However, the persistence of the gummy smile was observed (Figure 6). In the same treatment session, botulinum toxin was applied. Prior to application, the surface of the skin was disinfected with ethanol, to avoid local infection and remove the skin oiliness. Posteriorly, local anesthetic (Emla ${ }^{\mathrm{TM}}$ Astra, São Paulo, Brazil) was applied, with the purpose to promote comfort during the procedure. The botulinum toxin type A Botox $^{\mathrm{TM}} 200$ units, Allergan Pharmaceuticals, Westport, Ireland) was diluted in $2 \mathrm{ml}$ of saline solution, according to the manufacturer's instructions, and two units were injected at the recommended site, laterally to each nostril, at the level of the nose wing, at the insertion of the levator labii superioris alaeque nasi muscle. After application, the patient was advised to not lower her head and not engage in physical activity during the first four hours after the procedure.

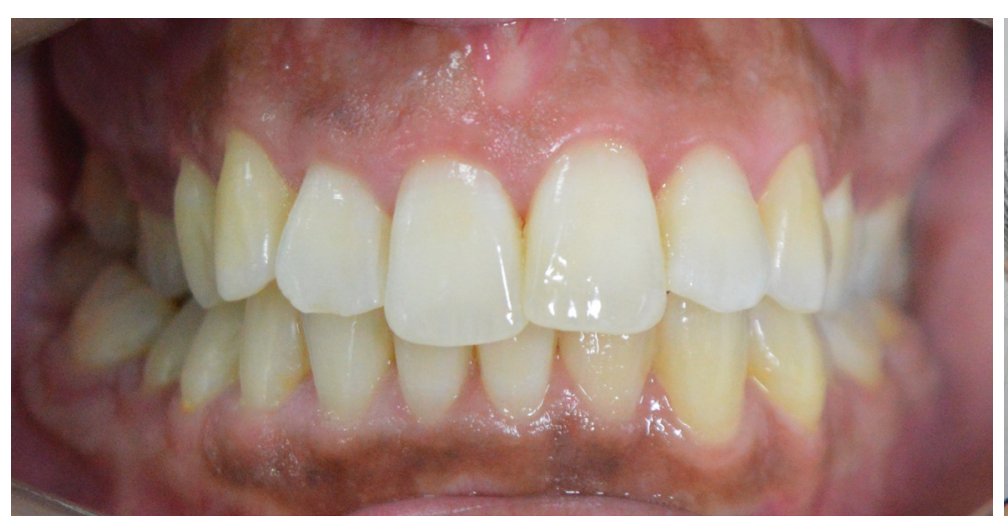

Figure 5: Post-operative (30 days) after gingivoplasty.

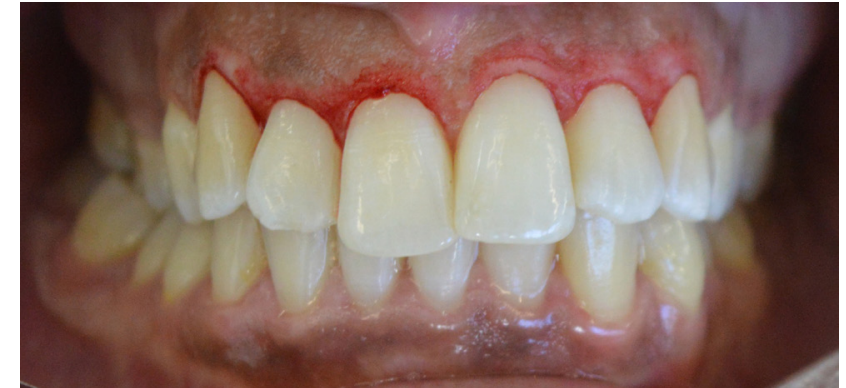

Figure 4: Immediate post-operative view after gingivoplasty.

After 15 days, the patient was evaluated. She presented uniform dehiscence of the upper lip (Figure 7). Side effects or complaints were not reported. The clinical effect of botulinum toxin application remained for six months.

\section{DISCUSSION}

Several aetiologies were suggested to the gummy smile, like the vertical excess of maxilla, ${ }^{1,4-8}$ delayed passive eruption, ${ }^{1,4,6,8}$ hyperfunction of the muscles involved in the smile ${ }^{1,6,8}$ and reduced length of the teeth clinical crown, ${ }^{1-3}$ which may occur singly or in combination, and determine the type of treatment to be applied. In gummy smile caused by muscular hyperfunction, botulinum toxin was indicated. It is the treatment of first choice for the facility and security of applications, besides being a more conservative approach when compared to surgical procedures (myectomy or Le Fort I osteotomy). ${ }^{1,4,10}$

The smile activity is determined by several facial muscles, such as the levator labii superioris, the levator labii superioris alaeque nasi, and the zygomaticus major and minor. ${ }^{1,4-9}$ The fibers of these muscles converge to the same area, forming a triangle, suggesting that the appropriate election point comprehends the three muscles in a single injection. The proposed site of the injection lateral to the wing of the nose (ala). ${ }^{1,4,7-9}$ The toxin, when injected, can be spread in an area of $20 \mathrm{~mm}$, allowing the effective extension. ${ }^{1,4,5}$ The toxin decreases the contraction of muscles responsible for the elevation of the upper lip, reducing gingival exposure. ${ }^{4-9}$

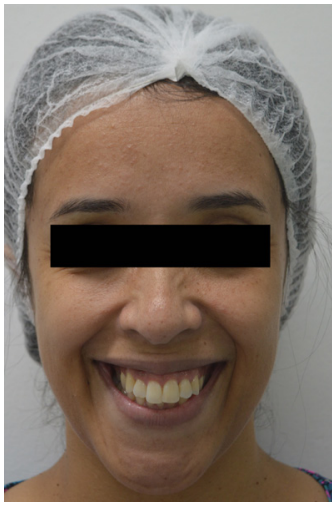

Figure 6: Persistence of the gummy smile after gingivoplasty.

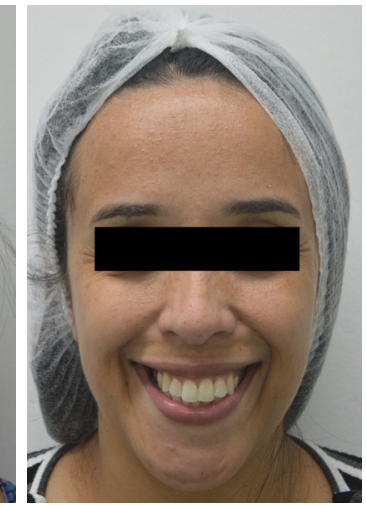

Figure 7: Result presented after 15 days of botulinum toxin application. 
The botulinum toxin is a hydrophilic powder, stored under vacuum, sterile and stable conditions... ${ }^{1,6,7}$ The reconstitution occurs from the smooth injection of the diluent (sodium chloride $0.9 \%$ ) into the bottle, and it have to be stored at 2 to $8^{\circ} \mathrm{C}$, and used within four to eight hours, in order to guarantee its effectiveness. ${ }^{1,8}$

Clinical effects present into 2-10 days after the injection, and the maximum visible effect occurs after 14 days of injection. ${ }^{1,4,6}$ This effect last approximately 3-6 months. ${ }^{1,5,6,8}$

Contraindications to the use of botulinum toxin include: pregnant and lactating women, patients with neurodegenerative and autoimmune diseases, and concurrent use of aminoglycoside antibiotic that enhances the action of the toxin. ${ }^{1,8}$
In this report, the result was satisfactory to the harmony of the smile by association of treatments - gingivoplasty and application of botulinum toxin. The institution of isolated treatments could not culminate in the excellence of the earned results. Initially, the creation of the new dental zenith after gingivoplasty promoted the new dental architecture, favouring harmony of gingival-dental-facial architecture for the patient. Subsequently, the application of botulinum toxin reduced the gummy smile, by the uniform dehiscence itself of the upper lip, still promoting smoothness to facial lines of the smile, as can be seen in the nasolabial folds, adjacent to the nostrils, comparing Figures 1 and 7 .

\section{REFERENCES}

1. Pedron IG. Toxina botulínica - Aplicações em Odontologia. First Edition. Florianópolis: Ed. Ponto. 2016.195 pages.

2. Narayan S, Narayan TV, Jacob PC. Correction of gummy smile: a report of two cases. J Indian Soc Periodontol. 2011;15:421-4.

3. Pedron IG, Utumi ER, Silva LPN, Moretto EML, Lima TCF, Ribeiro MA. Gingival resective surgery to the treatment of disharmony of smile. Rev Odontol Bras Central. 2010;18:87-91.

4. Hwang WS, Hur MS, Hu KS, Song WC, Koh KS, Baik HS, et al. Surface anatomy of the lip elevator muscles for the treatment of gummy smile using botulinum toxin. Angle Orthod. 2009;79:70-7.

5. Mazzuco R, Hexsel D. Gummy smile and botulinum toxin: A new approach based on the gingival exposure area. J Am Acad Dermatol. 2010;63:1042-51.

6. Polo M. Botulinum toxin type A in the treatment of excessive gingival display. Am J Orthod Dentofacial Orthop 2005;127:214-8.

7. Indra AS, Biswas PP, Vineet VT, Yeshaswini T. Botox as an adjunct to orthognathic surgery for a case of severe vertical maxillary excess. J Maxillofac Oral Surg 2011;10:226-70.

8. Pijpe J, Jansma J. The use of botulinum toxin type A in cosmetic facial procedures. Int J Oral Maxillofac Surg 2011;40:127-33.

9. Sucupira E, Abramovitz A. A simplified method for smile enhancement: botulinum toxin injection for gummy smile. Plast Reconstr Surg 2012;130:726-8.

10. Niamtu J 3rd. Botox injections for gummy smiles. Am J Orthod Dentofacial Orthop 2008;133:782-3. 